\title{
Association between Dopamine Transporter Gene (DAT1) Polymorphisms and Eating Disorders with Binge Eating Behavior
}

\author{
Takashi Hirata $^{1 *}$, Takuji Uemura1, Manabu Shinohara², Masami Hirano³ \\ ${ }^{1}$ Department of Neuropsychiatry and Clinical Ethics, Interdisciplinary Graduate School of Medicine, University of Yamanashi, \\ Yamanashi, Japan \\ ${ }^{2}$ Health Care Center, University of Yamanashi, Yamanashi, Japan \\ ${ }^{3}$ Kyosai Hospital, Yamanashi, Japan \\ Email: *thirata@yamanashi.ac.jp
}

How to cite this paper: Hirata, T., Uemura, T., Shinohara, M. and Hirano, M. (2017) Association between Dopamine Transporter Gene (DAT1) Polymorphisms and Eating Disorders with Binge Eating Behavior. Open Journal of Psychiatry, 7, 329-343.

https://doi.org/10.4236/ojpsych.2017.74028

Received: August 23, 2017

Accepted: September 17, 2017

Published: September 20, 2017

Copyright () 2017 by authors and Scientific Research Publishing Inc. This work is licensed under the Creative Commons Attribution International License (CC BY 4.0).

http://creativecommons.org/licenses/by/4.0/

\begin{abstract}
Objectives: Dyshomeostasis of the dopaminergic system is implicated in the pathophysiology of eating disorders (EDs). We have previously reported an association between 3'-UTR VNTR (three prime untranslated region variable number of tandem repeat) of the Dopamine Transporter 1 (DAT1) gene and ED with binge eating behavior (EDBEB). Here we investigated whether variants in the coding region of the DAT1 gene also associate with EDBEB. Methods: The coding region and exon-intron junctions of the DAT1 gene were screened by direct sequencing using genomic DNA from EDBEB patients $(\mathrm{n}=90)$ and healthy subjects $(\mathrm{n}=114)$ on whom 3'-UTR VNTR variants had been previously determined. Results: rs2270912 and rs28363130, two of five known polymorphisms found by this screen, were significantly associated with EDBEB patients by genotype ( $p=0.003, p=0.011$, respectively) and allele ( $p=0.003, p=0.012$, respectively) frequency compared with healthy subjects. Interestingly, these polymorphisms associate with the risk 3'-UTR VNTR variant of EDBEB. Conclusion: Although our sample size was small, we show here that rs2270912 and rs28363130 associates with EDBEB and might act with 3'-UTR VNTR as a haplotype. These findings support the notion that the $D A T 1$ gene plays a key role in the dopaminergic system of EDBEB.
\end{abstract}

\section{Keywords}

Eating Disorder, Binge Eating Behavior, DAT1, 
Association Study, Polymorphism

\section{Introduction}

Eating disorders (EDs) are psychiatric disorders that include abnormal eating behaviors, such as refusing to eat (restrictive eating) and overeating (binge eating) or excretory behaviors to prevent weight gain by vomiting food or using laxatives and diuretics, which often develop among young women who are between the stages of late puberty and early adulthood [1] [2]. In particular, ED with binge eating behavior (EDBEB) are often accompanied by abnormal eating behavior and alcohol or drug dependence [3] [4], mood swings such as depression and being easily upset, or character changes [1], which lead to impulsive behaviors such as shoplifting, sexual promiscuity [5], self-mutilation, or attempting suicide [6].

The development of EDs has been indicated to be affected by not only a psychosocial sense of value, such as extreme obsession with weight, e.g., being skinny means being beautiful, but also genetic factors [7]. Therefore, the development of ED and its disease state is currently considered to be associated with psychosocial factors that are closely related to genetic factors [8], which is similar to mental disorders such as bipolar disorder and schizophrenia. To elucidate the development of ED and its disease state, clinical genetic studies such as twin studies [9], family studies [10], and various genome-wide association studies (GWASs) are being conducted; however, no consensus on the results regarding candidate genes for ED has been reached [7] [11] [12].

The dopamine system greatly affects emotions, substance dependence, and eating behaviors [13] [14]. Abnormalities in the dopamine system have been indicated in the pathophysiology of ED [14]. A gene that plays an important role in the dopamine system is the solute carrier family 6 member 3 (SLC6A3, Gene ID: 6531), alternatively known as $D A T$ (dopamine transporter) or $D A T 1$ (hereinafter, $D A T 1$ is used). The $D A T 1$ gene encodes a transmembrane protein that regulates dopamine reuptake from synapses and possesses variable number of tandem repeats (VNTRs) in its 3'-untranslated region (3'-UTR) [15]. Polymorphisms in the number of repeats influence DAT1 gene expression [16]. Besides ED [17], the associations of polymorphisms with attention-deficient/hyperactivity disorder [18], alcohol [19], smoking [20], and cocaine dependence [21], and schizophrenia [22] are known.

From our group, Shinohara et al. previously reported the association between EDBEB and 3'-UTR VNTRs in the DAT1 gene by comparing seven or nine VNTR short alleles with 10 or 11 VNTR long alleles [23]. However, no study has assessed the association between EDBEB and regions other than the 3'-UTR VNTRs in the DAT1 gene. Therefore, in this study, we conducted a genetic polymorphism analysis by focusing on the coding region of the $D A T 1$ gene using a previously studied Japanese sample set and closely reinvestigated the association 
between EDBEB and the DAT1 gene.

\section{Subjects and Methods}

\subsection{Subjects}

In this study, we employed the sample sets previously used by Shinohara et al. [23] to assess the association between EDBEB and polymorphisms in the 3'-UTR VNTRs in the DAT1 gene. However, among the healthy subject group, the genomic DNA of one patient was depleted. The total number of subjects in the patient group with EDBEB was 90 (Japanese females: mean $22.1 \pm$ SD (standard deviation) 4.0 years) and that in the healthy subject group was 114 (Japanese females: mean $18.7 \pm$ SD 1.1 years). Diagnostic assessment and characteristics of the subjects are as previously reported [23] [24]. Patients with EDBEB were required to satisfy the diagnostic criteria described in the Diagnosis and Statistical Manual of Mental Disorders, $4^{\text {th }}$ Edition [25], have a history of visiting a hospital that specialized in treating patients with $\mathrm{ED}$ for $>3$ years, and have no changes in the diagnosis over a 3-year period. In addition, symptoms were evaluated according to the Eating Disorder Inventory [26]. The healthy subject group included individuals whose weights were maintained with fluctuations within $20 \%$ of the standard body weight. Furthermore, after obtaining the approval of the Ethics Committee of the University of Yamanashi, this study was conducted with individuals who provided informed consent after receiving written and oral explanations before initiating the study. Moreover, the study was anonymized by giving each sample a number to prevent the identification of individuals and protect private information.

\subsection{Extraction of Genomic DNA}

Genomic DNA was extracted from the peripheral blood of test subjects using a QIAamp DNA Blood Kit (Qiagen, Tokyo, Japan). Genomic DNA was stored frozen at $-20^{\circ} \mathrm{C}$ until the tests mentioned below were conducted.

\subsection{Polymerase Chain Reaction}

Intron-exon information of the DAT1 gene was confirmed from the DAT1 mRNA sequence (SLC6A3: NM_001044) and DAT1 gene sequence (NG_015885). Using this information, exons (from exon 2 to 14) that corresponded to the coding region of the $D A T 1$ gene were amplified by polymerase chain reaction (PCR) using the genomic DNA of each test subject as a template. Each primer was designed using the nucleotide sequence of the $D A T 1$ gene as a reference, with primers homologous to the upstream and downstream intron sequences bordering each exon (Table 1). The nucleotide sequences of both exon 2 and 4 are long; therefore, each exon was split into overlapping fragments and then amplified using each specific primer pair (Table 1). PCR was performed using the PCR System 9700 (Thermo Fisher Scientific Inc., Waltham, MA, USA), and conditions for each PCR cycle are shown in Table 2. PCR products were 
Table 1. List of PCR primers.

\begin{tabular}{|c|c|c|c|c|}
\hline Fragment & Forward primer $\left(5^{\prime} \rightarrow 3^{\prime}\right)$ & $\begin{array}{c}\mathrm{Tm} \\
\left({ }^{\circ} \mathrm{C}\right)\end{array}$ & Reverse primer $\left(5^{\prime} \rightarrow 3^{\prime}\right)$ & $\begin{array}{c}\mathrm{Tm} \\
\left({ }^{\circ} \mathrm{C}\right)\end{array}$ \\
\hline Exon $2-1^{a}$ & CTGAAGACCAAGAGGGAAGA & 52 & CAATGACGGACAGGAGAAAG & 52 \\
\hline Exon $2-2^{a}$ & CAAGGAGCAGAACGGAGTG & 53 & GGAGGCTGAGATGGGACTT & 53 \\
\hline Exon 3 & TCCGAGGCCCCAAACTAAA & 51 & ATGATGCGGCTGGCTTGCT & 53 \\
\hline Exon $4-1^{a}$ & TGATGGTGGCTCTGTGCTC & 53 & GTGGTCCCAAAAGTGTCGT & 51 \\
\hline Exon $4-2^{a}$ & GGGCGCTGCACTATCTCTT & 53 & TCCAACCAAGGGGCTACCA & 53 \\
\hline Exon 5 & TTGACAGCCACCCACAGAGT & 54 & AGCACAAAACCCAACTGAGG & 52 \\
\hline Exon 6 & GCGTCCCAGGAAATGTTTG & 51 & CCCTGTGGACTGTGAAGCA & 53 \\
\hline Exon 7 & GCATCTTCCACCAGTCGTCT & 54 & TGTTCTCATCCAGGGACACC & 54 \\
\hline Exon 8 & CСTTCCCCAGACACAGTAA & 51 & AAAAAGGCTTTGCTGAGAG & 47 \\
\hline Exon 9 & TTCAGCAGAGCCGCACCAG & 55 & GAACCCAACTGCCGAGGAC & 55 \\
\hline Exon 10 & CCGACCCTGTGCTCTGTGT & 55 & GTGCTGCGGTTCTGTCTGG & 55 \\
\hline Exon 11 & GGGTTGAATTTTAGGGACTC & 50 & CACAGCCACCAAACAAGAGG & 54 \\
\hline Exon 12 & ACTGATGCCACCTCTTCTCC & 54 & CTCCAGCCACAGTGACAACC & 56 \\
\hline Exon 13 & GCCTGACCTCCGTATCTGCT & 56 & ACACCCACGGAGCCTTTCTG & 56 \\
\hline Exon 14 & GTGAGGGTGCTGGTAGGTGA & 56 & CTGGGGGCTAAGAACACTGA & 54 \\
\hline
\end{tabular}

${ }^{\mathrm{a}}$ As the nucleotide sequences of exons 2 and 4 are long, each exon was split into overlapping fragments and amplified by each specific primer pair.

Table 2. PCR conditions for the amplification of each exon of the DAT1 gene.

\begin{tabular}{lllllllc}
\hline Fragment & Predenature & Denature & Annealing & Extension & Cycles & Extension & Size (bp) \\
\hline Exon 2-1 & $94^{\circ} \mathrm{C}, 2 \mathrm{~min}$ & $94^{\circ} \mathrm{C}, 15 \mathrm{~s}$ & $64^{\circ} \mathrm{C}, 30 \mathrm{~s}$ & $68^{\circ} \mathrm{C}, 18 \mathrm{~s}$ & 35 & $68^{\circ} \mathrm{C}, 4 \mathrm{~min}$ & 274 \\
Exon 2-2 & $94^{\circ} \mathrm{C}, 2 \mathrm{~min}$ & $94^{\circ} \mathrm{C}, 15 \mathrm{~s}$ & $60^{\circ} \mathrm{C}, 30 \mathrm{~s}$ & $68^{\circ} \mathrm{C}, 14 \mathrm{~s}$ & 35 & $68^{\circ} \mathrm{C}, 4 \mathrm{~min}$ & 206 \\
Exon 3 & $94^{\circ} \mathrm{C}, 2 \mathrm{~min}$ & $94^{\circ} \mathrm{C}, 15 \mathrm{~s}$ & $60^{\circ} \mathrm{C}, 30 \mathrm{~s}$ & $68^{\circ} \mathrm{C}, 21 \mathrm{~s}$ & 35 & $68^{\circ} \mathrm{C}, 4 \mathrm{~min}$ & 258 \\
Exon 4-1 & $94^{\circ} \mathrm{C}, 2 \mathrm{~min}$ & $94^{\circ} \mathrm{C}, 15 \mathrm{~s}$ & $68^{\circ} \mathrm{C}, 30 \mathrm{~s}$ & $68^{\circ} \mathrm{C}, 18 \mathrm{~s}$ & 35 & $68^{\circ} \mathrm{C}, 4 \mathrm{~min}$ & 271 \\
Exon 4-2 & $94^{\circ} \mathrm{C}, 2 \mathrm{~min}$ & $94^{\circ} \mathrm{C}, 15 \mathrm{~s}$ & $60^{\circ} \mathrm{C}, 30 \mathrm{~s}$ & $68^{\circ} \mathrm{C}, 21 \mathrm{~s}$ & 35 & $68^{\circ} \mathrm{C}, 4 \mathrm{~min}$ & 243 \\
Exon 5 & $94^{\circ} \mathrm{C}, 2 \mathrm{~min}$ & $94^{\circ} \mathrm{C}, 15 \mathrm{~s}$ & $60^{\circ} \mathrm{C}, 30 \mathrm{~s}$ & $68^{\circ} \mathrm{C}, 21 \mathrm{~s}$ & 35 & $68^{\circ} \mathrm{C}, 4 \mathrm{~min}$ & 291 \\
Exon 6 & $94^{\circ} \mathrm{C}, 2 \mathrm{~min}$ & $94^{\circ} \mathrm{C}, 15 \mathrm{~s}$ & $66^{\circ} \mathrm{C}, 30 \mathrm{~s}$ & $68^{\circ} \mathrm{C}, 21 \mathrm{~s}$ & 35 & $68^{\circ} \mathrm{C}, 4 \mathrm{~min}$ & 311 \\
Exon 7 & $94^{\circ} \mathrm{C}, 2 \mathrm{~min}$ & $94^{\circ} \mathrm{C}, 15 \mathrm{~s}$ & $58^{\circ} \mathrm{C}, 30 \mathrm{~s}$ & $68^{\circ} \mathrm{C}, 21 \mathrm{~s}$ & 35 & $68^{\circ} \mathrm{C}, 4 \mathrm{~min}$ & 350 \\
Exon 8 & $94^{\circ} \mathrm{C}, 2 \mathrm{~min}$ & $94^{\circ} \mathrm{C}, 15 \mathrm{~s}$ & $60^{\circ} \mathrm{C}, 30 \mathrm{~s}$ & $68^{\circ} \mathrm{C}, 21 \mathrm{~s}$ & 35 & $68^{\circ} \mathrm{C}, 4 \mathrm{~min}$ & 291 \\
Exon 9 & $94^{\circ} \mathrm{C}, 2 \mathrm{~min}$ & $94^{\circ} \mathrm{C}, 15 \mathrm{~s}$ & $60^{\circ} \mathrm{C}, 30 \mathrm{~s}$ & $68^{\circ} \mathrm{C}, 18 \mathrm{~s}$ & 35 & $68^{\circ} \mathrm{C}, 4 \mathrm{~min}$ & 289 \\
Exon 10 & $94^{\circ} \mathrm{C}, 2 \mathrm{~min}$ & $94^{\circ} \mathrm{C}, 15 \mathrm{~s}$ & $68^{\circ} \mathrm{C}, 30 \mathrm{~s}$ & $68^{\circ} \mathrm{C}, 16 \mathrm{~s}$ & 35 & $68^{\circ} \mathrm{C}, 4 \mathrm{~min}$ & 254 \\
Exon 11 & $94^{\circ} \mathrm{C}, 2 \mathrm{~min}$ & $94^{\circ} \mathrm{C}, 15 \mathrm{~s}$ & $60^{\circ} \mathrm{C}, 30 \mathrm{~s}$ & $68^{\circ} \mathrm{C}, 18 \mathrm{~s}$ & 35 & $68^{\circ} \mathrm{C}, 4 \mathrm{~min}$ & 284 \\
Exon 12 & $94^{\circ} \mathrm{C}, 2 \mathrm{~min}$ & $94^{\circ} \mathrm{C}, 15 \mathrm{~s}$ & $60^{\circ} \mathrm{C}, 30 \mathrm{~s}$ & $68^{\circ} \mathrm{C}, 21 \mathrm{~s}$ & 35 & $68^{\circ} \mathrm{C}, 4 \mathrm{~min}$ & 233 \\
Exon 13 & $94^{\circ} \mathrm{C}, 2 \mathrm{~min}$ & $94^{\circ} \mathrm{C}, 15 \mathrm{~s}$ & $68^{\circ} \mathrm{C}, 30 \mathrm{~s}$ & $68^{\circ} \mathrm{C}, 16 \mathrm{~s}$ & 35 & $68^{\circ} \mathrm{C}, 4 \mathrm{~min}$ & 259 \\
Exon 14 & $94^{\circ} \mathrm{C}, 2 \mathrm{~min}$ & $94^{\circ} \mathrm{C}, 15 \mathrm{~s}$ & $66^{\circ} \mathrm{C}, 30 \mathrm{~s}$ & $68^{\circ} \mathrm{C}, 16 \mathrm{~s}$ & 35 & $68^{\circ} \mathrm{C}, 4 \mathrm{~min}$ & 251 \\
\hline & & & & & & &
\end{tabular}


electrophoresed using 2\% agarose gel containing ethidium bromide, and each PCR product was confirmed as having the expected length after exposing the gel to ultraviolet (UV) light. The lengths of each PCR product are shown in Table 2.

\subsection{Nucleotide Sequencing Analysis of Polymerase Chain Reaction Products}

To investigate mutations in the DAT1 gene, the nucleotide sequence of each PCR product was analyzed by direct sequencing. PCR products were electrophoresed using $2 \%$ agarose gel containing ethidium bromide, and each PCR product with the predicted length was observed under UV light. Each PCR product was extracted from gels using a Microcon centrifugal filter (EMD Millipore Corp., Billerica, MA, USA) and purified. The nucleotide sequence of each purified PCR product was determined by direct sequencing using an ABI $377 \mathrm{~S}$ DNA sequencer (PerkinElmer Japan Co., Ltd., Kanagawa, Japan).

\subsection{Statistical Analysis}

Hardy-Weinberg equilibrium analysis (HWE) of each obtained genotype and an association study of the patient group with the healthy subject group were conducted using SNPAlyze Ver.8.0.1 Standard (DYNACOM, Chiba, Japan). However, some identified polymorphisms were not analyzed according to the Hardy-Weinberg equilibrium; therefore, the Cochran-Armitage trend test was performed for the association study. Statistical power was evaluated using single nucleotide polymorphism (SNP) tools

(http://www.bioinformatics.org/snp-tools-excel) [27]. P values of $<0.05$ were considered to be statistically different. Because of the small sample size, an association study of identified polymorphisms with the 3'-UTR VNTR was performed only for haplotype frequency.

\section{Results}

\subsection{Genetic Polymorphism Analysis of the DAT1 Gene}

Exons 2-14 of the DAT1 gene were amplified by PCR using genomic DNA from each test sample (total of 204 samples: 90 samples from the patient group and 114 samples from the healthy subject group) as the template and using primers designed such that each primer was homologous to the upstream and downstream intron sequences that bordered each exon. The nucleotide sequence of each sequence was then analyzed by direct sequencing. Five polymorphisms, namely rs460000 $(\mathrm{C} \rightarrow \mathrm{A})$ located in intron 3, rs6347 $(\mathrm{A} \rightarrow \mathrm{G}$ ) located in exon 9, rs2270912 $(\mathrm{C} \rightarrow \mathrm{T}$ ) located in exon 10, rs429699 ( $\rightarrow \mathrm{A}$ ) located in intron 11, and rs28363130 $(A \rightarrow G)$ located in intron 13, were identified; however, all these polymorphisms were already registered in GenBank ${ }^{\oplus}$ (https://www.ncbi.nlm.nih.gov/genbank/). Furthermore, rs6347 and rs2270912 were polymorphisms that did not cause amino acid substitutions, although they were located in exons (Figure 1 and Table 3). 


\section{Loci of polymorphisms in the $D A T 1$ gene}

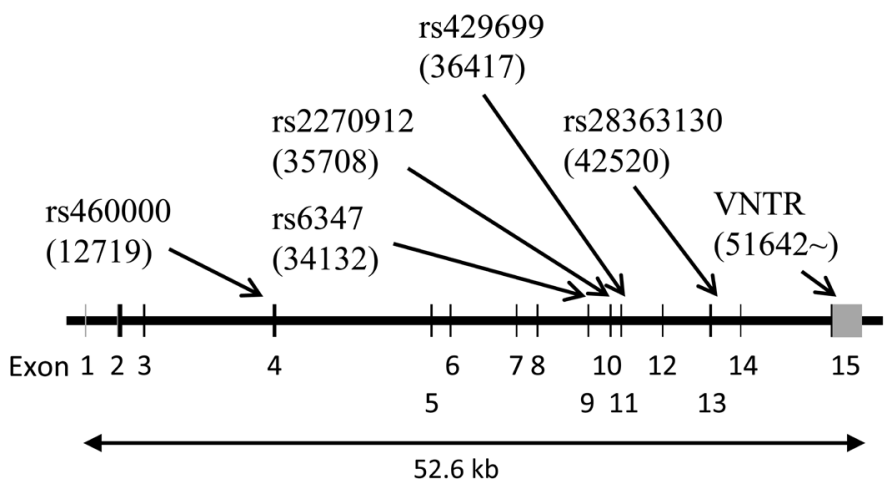

Figure 1. Loci of polymorphisms in the DAT1 gene. The DAT1 gene is approximately $52.6 \mathrm{~kb}$ and contains 15 exons. All exons are indicated as a box, and noncoding regions are shown in gray boxes and coding regions are shown in black boxes. The locations of five polymorphisms and 3'-untranslated region variable number of tandem repeats (UTR VNTRs) in the DAT1 gene are shown. Numbers shown in parentheses indicate the locations of each polymorphism from the first nucleotide of exon 1 of the DAT1 gene (NG_015885). Rs460000 $(\mathrm{C} \rightarrow \mathrm{A})$ is located 12 nucleotides upstream from the first nucleotide of exon 4. Rs6347 $(\mathrm{A} \rightarrow \mathrm{G})$, a polymorphism that does not cause an amino acid substitution, is located 59 nucleotides downstream from the first nucleotide of exon 9, whereas rs2270912 $(\mathrm{C} \rightarrow \mathrm{T})$, a polymorphism that also does not cause amino acid substitution, is located at the last nucleotide of exon 10. Rs429699 ( $\rightarrow$ A) is a polymorphism that is located 14 nucleotides downstream from the first nucleotide of intron 11, whereas rs28363130 $(A \rightarrow G)$ is a polymorphism located 13 nucleotides downstream from the first nucleotide of intron 13. 3'-UTR VNTRs are located within exon 15.

Table 3. Location of identified DAT1 polymorphisms.

\begin{tabular}{lcccl}
\hline dbSNP ID & Sequence change & Position $^{\mathrm{a}}$ & Protein variant & Location \\
\hline rs460000 & $\mathrm{C} \rightarrow \mathrm{A}$ & 12719 & - & Intron 3 \\
rs6347 & $\mathrm{A} \rightarrow \mathrm{G}$ & 34132 & Ser 405 Ser & Exon 9 \\
rs2270912 & $\mathrm{C} \rightarrow \mathrm{T}$ & 35708 & Asn 466 Asn & Exon 10 \\
rs429699 & $\mathrm{G} \rightarrow \mathrm{A}$ & 36417 & - & Intron 11 \\
rs28363130 & $\mathrm{A} \rightarrow \mathrm{G}$ & 42520 & - & Intron 13
\end{tabular}

${ }^{\text {aThe }}$ position of each identified polymorphism was relative to the first nucleotide of exon 1 of the DATI gene (NG_015885).

\subsection{Genotype Frequency and Hardy-Weinberg Equilibrium}

The possible genotypes of $\mathrm{rs} 460000(\mathrm{C} \rightarrow \mathrm{A})$ were $\mathrm{C} / \mathrm{C}, \mathrm{C} / \mathrm{A}$, and $\mathrm{A} / \mathrm{A}$, with the number of test samples in each genotype being 25 (27.8\%), 48 (53.3\%), and 17 (18.95\%), respectively, in the patient group and 27 (23.7\%), 60 (52.6\%), and 27 (23.7\%), respectively, in the healthy subject group. HWE showed a $p$ value of 0.530 in the patient group and a $\mathrm{p}$ value of 0.708 in the healthy subject group; thus, no significant differences were observed in either group, and they agreed with the HWE. 
The possible genotypes of $\operatorname{rs6347}(\mathrm{A} \rightarrow \mathrm{G}$ ) were $\mathrm{A} / \mathrm{A}, \mathrm{A} / \mathrm{G}$, and $\mathrm{G} / \mathrm{G}$, with the number of test samples in each genotype being 67 (74.7\%), 23 (25.6\%), and 0 (0\%), respectively, in the patient group and 98 (86.0\%) 13 (11.4\%), and $3(2.6 \%)$, respectively, in the healthy subject group. The HWE showed no significant differences in the patient group $(p=0.346)$; thus, the values agreed with HWE. However, it showed significant differences in the healthy subject group ( $\mathrm{p}=$ 0.027), and the values did not agree with the HWE.

The possible genotypes of $\mathrm{rs} 2270912(\mathrm{C} \rightarrow \mathrm{T})$ were $\mathrm{C} / \mathrm{C}, \mathrm{C} / \mathrm{T}$, and $\mathrm{T} / \mathrm{T}$, with the number of test samples in each genotype being 83 (92.2\%), 7 (7.8\%), and 0 (0\%), respectively, in the patient group and $114(100 \%), 0(0 \%)$, and $0(0 \%)$, respectively, in the healthy subject group. No samples with T/T were present in both the groups, and no samples with $\mathrm{C} / \mathrm{T}$ were present in the healthy subject group; therefore, the HWE analysis was not performed.

The possible genotypes of rs429699 (G $\rightarrow$ A) were G/G, G/A, and A/A, with the number of test samples in each genotype being 35 (38.9\%), $41(45.6 \%)$, and $14(15.6 \%)$, respectively, in the patient group and 48 (42.1\%), 53 (46.5\%), and 13 (11.4\%), respectively, in the healthy subject group. The HWE showed a p value of 0.823 in the patient group and a $\mathrm{p}$ value of 0.839 in the healthy subject group; thus, no significant differences were observed in either group, and the differences agreed with the HWE.

The possible genotypes of $\mathrm{rs} 28363130(\mathrm{~A} \rightarrow \mathrm{G})$ were $\mathrm{A} / \mathrm{A}, \mathrm{A} / \mathrm{G}$, and $\mathrm{G} / \mathrm{G}$, with the number of test samples in each genotype being $82(91.1 \%), 8(8.9 \%)$, and 0 (0\%), respectively, in the patient group and $113(99.1 \%), 1(0.9 \%)$, and $0(0 \%)$ in the healthy subject group. As no samples with G/G were present in either group, the HWE analysis was not performed. Furthermore, genotype frequency and HWE of each genotype in the patient and healthy subject groups are shown in Table 4.

\subsection{Association Study by the Cochran-Armitage Trend Test}

The allelic frequency of each C and A allele of rs460000 was 54.4\% (98 alleles) and $45.6 \%$ ( 82 alleles), respectively, in the patient group and 50.0\% (114 alleles) and $50.0 \%$ (114 alleles), respectively, in the healthy subject group. Thus, no significant difference was observed in the allelic frequency between the two groups $(p=0.357)$.

The allelic frequency of each A and G allele of rs6347 was $87.2 \%$ (157 alleles) and $12.8 \%$ (23 alleles), respectively, in the patient group and 91.7\% (209 alleles) and 19\% (83 alleles), respectively, in the healthy subject group. Thus, no significant difference was observed in the allelic frequency between the two groups $(p=0.151)$.

The allelic frequency of each C and T allele of rs2270912 was $96.1 \%$ (173 alleles) and 3.9\% (7 alleles), respectively, in the patient group and 100\% (228 alleles) and $0 \%$ (0 allele), respectively, in the healthy subject group. Therefore, a significant difference was observed in the allelic frequency between the two 
Table 4. Genotype and Allelic frequencies of the DAT1 gene in the EDBEB patient and healthy subject groups.

\begin{tabular}{|c|c|c|c|c|c|c|c|}
\hline \multirow[b]{2}{*}{ rs 460000} & \multirow[b]{2}{*}{$\mathrm{C} / \mathrm{C}^{\mathrm{a}}$} & \multicolumn{2}{|l|}{ Genotype } & \multirow[t]{2}{*}{$\begin{array}{l}\text { HWE } \\
p \text { value }\end{array}$} & \multicolumn{2}{|c|}{ Allele } & \multirow[t]{2}{*}{$P$ value $^{\mathrm{b}}$} \\
\hline & & $\mathrm{C} / \mathrm{A}^{\mathrm{a}}$ & $\mathrm{A} / \mathrm{A}^{\mathrm{a}}$ & & $\mathrm{C}^{\mathrm{a}}$ & $\mathrm{A}^{\mathrm{a}}$ & \\
\hline Patient & $\begin{array}{c}25 \\
(27.8 \%)\end{array}$ & $\begin{array}{c}48 \\
(53.3 \%)\end{array}$ & $\begin{array}{c}17 \\
(18.9 \%)\end{array}$ & $p=0.530$ & $\begin{array}{c}98 \\
(54.4 \%)\end{array}$ & $\begin{array}{c}82 \\
(45.6 \%)\end{array}$ & \multirow[b]{2}{*}{$p=0.357$} \\
\hline Healthy subject & $\begin{array}{c}27 \\
(23.7 \%)\end{array}$ & $\begin{array}{c}60 \\
(52.6 \%)\end{array}$ & $\begin{array}{c}27 \\
(23.7 \%)\end{array}$ & $p=0.708$ & $\begin{array}{c}114 \\
(50.0 \%)\end{array}$ & $\begin{array}{c}114 \\
(50.0 \%)\end{array}$ & \\
\hline rs6347 & $\mathrm{A} / \mathrm{A}$ & $\mathrm{A} / \mathrm{G}$ & $\mathrm{G} / \mathrm{G}$ & & A & G & \multirow{4}{*}{$p=0.151$} \\
\hline Patient & $\begin{array}{c}67 \\
(74.4 \%)\end{array}$ & $\begin{array}{c}23 \\
(25.6 \%)\end{array}$ & $\begin{array}{c}0 \\
(0.0 \%)\end{array}$ & $p=0.346$ & $\begin{array}{c}157 \\
(87.2 \%)\end{array}$ & $\begin{array}{c}23 \\
(12.8 \%)\end{array}$ & \\
\hline Healthy subject & $\begin{array}{c}98 \\
(86.0 \%)\end{array}$ & $\begin{array}{c}13 \\
(11.4 \%)\end{array}$ & $\begin{array}{c}3 \\
(2.6 \%)\end{array}$ & $p=0.027$ & $\begin{array}{c}209 \\
(91.7 \%)\end{array}$ & $\begin{array}{c}19 \\
(8.3 \%)\end{array}$ & \\
\hline rs2270912 & $\mathrm{C} / \mathrm{C}$ & $\mathrm{C} / \mathrm{T}$ & $\mathrm{T} / \mathrm{T}$ & & $\mathrm{C}$ & $\mathrm{T}$ & \\
\hline Patient & $\begin{array}{c}83 \\
(92.2 \%)\end{array}$ & $\begin{array}{c}7 \\
(7.8 \%)\end{array}$ & $\begin{array}{c}0 \\
(0.0 \%)\end{array}$ & $\mathrm{N} / \mathrm{A}^{\mathrm{c}}$ & $\begin{array}{c}173 \\
(96.1 \%)\end{array}$ & $\begin{array}{c}7 \\
(3.9 \%)\end{array}$ & \multirow[b]{2}{*}{$p=0.0024$} \\
\hline Healthy subject & $\begin{array}{c}114 \\
(100 \%)\end{array}$ & $\begin{array}{c}0 \\
(0.0 \%)\end{array}$ & $\begin{array}{c}0 \\
(0.0 \%)\end{array}$ & $\mathrm{N} / \mathrm{A}^{\mathrm{c}}$ & $\begin{array}{c}228 \\
(100 \%)\end{array}$ & $\begin{array}{c}0 \\
(0.0 \%)\end{array}$ & \\
\hline rs429699 & $\mathrm{G} / \mathrm{G}$ & G/A & $\mathrm{A} / \mathrm{A}$ & & G & A & \multirow{4}{*}{$p=0.443$} \\
\hline Patient & $\begin{array}{c}35 \\
(38.9 \%)\end{array}$ & $\begin{array}{c}41 \\
(45.6 \%)\end{array}$ & $\begin{array}{c}1 \\
(15.6 \%)\end{array}$ & $p=0.823$ & $\begin{array}{c}111 \\
(61.7 \%)\end{array}$ & $\begin{array}{c}69 \\
(38.3 \%)\end{array}$ & \\
\hline Healthy subject & $\begin{array}{c}48 \\
(42.1 \%)\end{array}$ & $\begin{array}{c}53 \\
(46.5 \%)\end{array}$ & $\begin{array}{c}13 \\
(11.4 \%)\end{array}$ & $p=0.839$ & $\begin{array}{c}149 \\
(65.4 \%)\end{array}$ & $\begin{array}{c}79 \\
(34.6 \%)\end{array}$ & \\
\hline rs28363130 & $\mathrm{A} / \mathrm{A}$ & $\mathrm{A} / \mathrm{G}$ & $\mathrm{G} / \mathrm{G}$ & & A & G & \\
\hline Patient & $\begin{array}{c}82 \\
(91.1 \%)\end{array}$ & $\begin{array}{c}8 \\
(8.9 \%)\end{array}$ & $\begin{array}{c}0 \\
(0.0 \%)\end{array}$ & $\mathrm{N} / \mathrm{A}^{\mathrm{c}}$ & $\begin{array}{c}172 \\
(95.6 \%)\end{array}$ & $\begin{array}{c}8 \\
(4.4 \%)\end{array}$ & \multirow{2}{*}{$p=0.0057$} \\
\hline Healthy subject & $\begin{array}{c}113 \\
(99.1 \%)\end{array}$ & $\begin{array}{c}1 \\
(0.9 \%)\end{array}$ & $\begin{array}{c}0 \\
(0.0 \%)\end{array}$ & $\mathrm{N} / \mathrm{A}^{\mathrm{c}}$ & $\begin{array}{c}227 \\
(99.6 \%)\end{array}$ & $\begin{array}{c}1 \\
(0.4 \%)\end{array}$ & \\
\hline
\end{tabular}

${ }^{a}$ Data presented as number of subjects and percentage. ${ }^{b} P$ values were calculated by the Cochran-Armitage Trend Test. 'N/A means not applicable.

groups $(p=0.0024)$. Statistical power analyses for allelic frequencies of rs2270912 could not be performed because no alleles of rs2270912 with T were found in the healthy subject group.

The allelic frequency of each $\mathrm{G}$ and A allele of rs429699 was $61.7 \%$ (111 alleles) and 38.3\% (69 alleles), respectively, in the patient group and 65.4\% (149 alleles) and $34.6 \%$ (79 allele), respectively, in the healthy subject group. Thus, no significant difference was observed in the allelic frequency between the two groups $(p=0.443)$.

The allelic frequency of each A and G allele of rs28363130 was $95.6 \%$ (172 alleles) and 4.4\% (8 alleles), respectively, in the patient group and 99.6\% (227 alleles) and $0.4 \%$ ( 1 allele), respectively, in the healthy subject group. A significant difference was observed in the allelic frequency of rs 28363130 between the two 
groups ( $p=0.0057$ ); however, the statistical power was 0.60 for the analysis of allelic frequencies of rs28363130. Genotype and allele frequencies of each polymorphism in EDBEB and healthy subject groups are shown in Table 4.

\subsection{Haplotype Analysis}

The associations of EDBEB with rs2270912, rs28363130, and 3'-UTR VNTR were investigated using haplotype analysis. However, the sample number was small, and homozygous rs2270912 $\mathrm{T}$ alleles, homozygous $\mathrm{rs} 28363130 \mathrm{G}$ alleles, and homozygous short 3 '-UTR VNTRs were not found in our sample sets. Therefore, haplotype frequencies alone were reported. Genetically, 27 haplotypes could be present; however, only six haplotypes were confirmed in the study. Among these haplotypes, the haplotype C/C-A/A-Long/Long (rs2270912-rs28363130-3'-UTR VNTR) was found to have the highest frequency in the patient group (76.7\%: 69/90 samples) and the healthy subject group (91.2\%: 104/114 samples) (Table 5).

All seven patient samples with the rs2270912 $\mathrm{T}$ allele, which was not found in the healthy subject group, possessed the short 3'-UTR VNTR, which is a risk allele for developing EDBEB. Furthermore, six of eight patient samples with the rs28363130 G allele had the short 3'-UTR VNTR; moreover, these six samples possessed the rs2270912 $\mathrm{T}$ allele (C/T-A/G-Long/Short; 6.7\%: 6/90 samples) (Table 5).

\section{Discussion}

An association study of the DAT1 gene with EDBEB was conducted using 204 genomic DNA samples obtained from 90 patients with EDBEB and 114 healthy subjects among Japanese females. All five polymorphisms found in the DAT1 gene in this study were already known. However, among these five polymorphisms, rs2270912 and rs28363130 showed a significant association with EDBEB. A significant association of rs6347 with EDBEB regarding the genotype frequency was found, although no significant association was found regarding

Table 5. Haplotype frequencies of the DAT1 gene in the EDBEB patient and healthy subject groups (rs2270912-rs28363130-3'-UTR VNTR).

\begin{tabular}{ccc}
\hline Haplotype $^{\mathrm{a}}$ & Patient $^{\mathrm{b}}$ & Healthy subject $^{\mathrm{b}}$ \\
\hline C/T-A/G-Long/Short & $6.7 \%(\mathrm{n}=6)$ & $0.0 \%(\mathrm{n}=0)$ \\
C/T-A/A-Long/Short & $1.1 \%(\mathrm{n}=1)$ & $0.0 \%(\mathrm{n}=0)$ \\
C/C-A/G-Long/Short & $0.0 \%(\mathrm{n}=0)$ & $0.9 \%(\mathrm{n}=1)$ \\
C/C-A/A-Long/Short & $13.3 \%(\mathrm{n}=12)$ & $7.9 \%(\mathrm{n}=9)$ \\
C/C-A/G-Long/Long & $2.2 \%(\mathrm{n}=2)$ & $0.0 \%(\mathrm{n}=0)$ \\
C/C-A/A-Long/Long & $76.7 \%(\mathrm{n}=69)$ & $91.2 \%(\mathrm{n}=104)$ \\
Total & $100 \%(\mathrm{n}=90)$ & $100 \%(\mathrm{n}=114)$ \\
\hline
\end{tabular}

a Shown in the order of rs2270912, rs28363130, and 3'-UTR VNTR; ' ${ }^{\mathrm{b}}$ ata presented as number of percentage and subjects. 
allele frequency. Among the seven EDBEB samples with the rs2270912 T allele, six possessed the rs $28363130 \mathrm{G}$ allele and the short 3'-UTR VNTR allele.

The polymorphism rs2270912 $(\mathrm{C} \rightarrow \mathrm{T})$ located in exon 10 is a silent mutation, which does not cause amino acid substitution. Silent mutations in the exon that are known as protein function, which is encoded by a gene containing a silent mutation, would not be affected because no amino acid substitution occurs. An increasing body of evidence revealed that silent mutations may have the ability to change in its encoded protein expression and structure [28]. ST8SIA2 (ST8 alpha- $\mathrm{N}$-acetyl-neuraminide alpha-2,8-sialyltransferase 2, Gene ID: 8128, alternatively known as $S T X$ ) that synthesizes polysialic acid involved in synaptic plasticity, the development of normal neural circuits and neurogenesis [29], is a susceptibility gene for schizophrenia, bipolar disorder, and autism spectrum disorder [30]. A functional genetic analysis of silent SNP $(C \rightarrow G)$, which is located in exon 5 of the $S T X$ gene, revealed that the enzymatic activity of STX protein decreased in the overexpressing mutant STX gene compared with that in the overexpressing wild-type STX gene in CHO cells [31]. From these reports, rs2270912, a polymorphism with a silent mutation, may alter the DAT1 protein structure, function, or activity.

Rs28363130 $(\mathrm{A} \rightarrow \mathrm{G})$ is a SNP found in intron 13 and located 13 bases upstream from the $5^{\prime}$ end of exon 13. Introns are regions of DNA that are removed during splicing after RNA transcription; therefore, rs28363130 itself does not influence the protein function encoded by the DAT1 gene. However, intronic SNP may be involved in splicing and regulating transcription. The presence of a transcriptional regulatory region specific to the $G$ allele, which causes a risk of developing EDBEB, as well as the expression of miRNA, is predicted to be present in the region that contains rs 28363130 by in silico analysis using RegRNA2.0 (http://regrna2.mbc.nctu.edu.tw/). This suggests that rs28363130 may affects the $D A T 1$ gene expression. However, in future, these in silico analysis derived predictions are requires validation by direct testing.

According to the Human Transporter Database (HTD: http://htd.cbi.pku.edu.cn/index.php) and the 1000 Genomes Project [32] [33], the minor allele frequency (MAF) of rs2270912 is 0.00367 . This means that 7.3 of 1000 subjects should have the $\mathrm{T}$ allele, which is an extremely low expression frequency. Of note, seven of 90 patients with EDBEB possessed the $\mathrm{T}$ allele, whereas none of the 114 healthy subjects possessed it in our sample sets. Thus, our study showed an approximate 11-fold higher expression frequency in subjects with the $\mathrm{T}$ allele in the patient group than that in the HTD and the 1000 Genomes Project. Furthermore, MAF of rs 28363130 is 0.00230 , and 4.6 of 1000 subjects should have the $\mathrm{G}$ allele. Eight of 90 subjects in the patient group possessed the G allele in our sample sets, which is approximately 19.3-fold higher in frequency than that shown by the HTD and the 1000 Genomes Project. Despite the small sample size of our study, the results suggested that both SNPs with $\mathrm{T}$ and $G$ alleles specifically occur in patients with EDBEB. 
On the basis of the haplotype analysis of rs2270912, rs28363130, and 3'-UTR VNTRs reported by Shinohara et al., where an association with patients with EDBEB was found, it was discovered that six of seven patients with EDBEB who had the rs2270912 $\mathrm{T}$ allele also possessed the rs28363130 $\mathrm{G}$ allele and the short 3'-UTR VNTR allele (haplotype: C/T-A/G-Long/Short; 6.7\%: 6/90 patients). In our sample sets, this haplotype was not present in the healthy subject group. Unfortunately, MAFs of rs2270912 and rs28363130 were extremely low, being 0.00367 and 0.00230 , respectively. Moreover, a homozygote of each rs $2270912 \mathrm{~T}$ allele, rs28363130 G allele, and short 3'-UTR VNTR was not present in our sample sets. Therefore, statistical analysis was not performed, and haplotype frequencies alone are presented in Table 5. This haplotype analysis revealed a possible association of the haplotype created by the $\mathrm{T}$ allele at rs2270912, the $\mathrm{G}$ allele at rs28363130, and short 3'-UTR VNTR with the susceptibility to patients with EDBEB.

Regarding 3'-UTR VNTR, there is a report that DAT1 expression is decreased in the striatum in the subject group with short 3'-UTR VNTR-440, where nine tandem repeats were observed in the 3 '-UTR VNTR [34], whereas there are reports indicating an increase in DAT1 expression [35] and no change in DAT1 expression [36]; thus, there is no consensus regarding DAT1 expression and short 3'-UTR VNTR-360. It has been reported that haplotypes, comprising mutations accompanied by a mutation with amino acid substitution and a silent mutation, can modify the expression and function of genes such as $A C B C 1$ (ATP-binding cassette subfamily B member 1), commonly known as multidrug resistance protein 1 , which encodes a $\mathrm{P}$-glycoprotein involved in drug resistance [37], and $N K X 2-5$ (NK2 homeobox 5), which is involved in congenital heart diseases [38]. From these reports, there is the possibility that the function of the $D A T 1$ gene can be modified by the haplotypes of 3'-UTR VNTR, rs2270912, and rs28363130. Moreover, it is believed that the molecular investigation of the haplotype rs2270912-rs28363130-3'-UTR VNTR will help in elucidating the significance of the haplotype in patients with EDBEB and in elucidating the reason why the results of the functional analysis of 3'-UTR VNTRs have not coincided with those. In the future, we plan to analyze this haplotypes in patients with EDBEB using a larger sample size.

The polymorphisms found in this study are SNPs that have not been identified by GWASs, which comprehensively searched for SNPs related to the diseases by a genome-wide search from thousands to tens of thousands of samples. Generally, GWASs use linkage disequilibrium directed toward known SNPs with MAFs of $>1 \%$. Therefore, unknown SNPs and SNPs with $<1 \%$ MAF cannot be analyzed. Moreover, SNPs that show an association with diseases by GWAS are not necessarily associated with the diseases. Therefore, detailed analyses that focus on SNP regions that show an association with diseases are sometimes necessary. While SNPs that we identified are known SNPs, MAFs of these SNPs are $<1 \%$. Therefore, it appears that they cannot be detected by GWASs. 
The prevalence of ED among young women has increased. However, molecular-supported subclassification and treatment methods for ED have not been completely established. While there is no question that abnormal eating behaviors and weight fluctuations are the main clinical conditions for patients with $\mathrm{ED}$, changes in the diagnosis and the course of treatment are highly dependent on the presence or absence of binge eating behaviors. This study's elucidation of the association between patients with EDBEB and $D A T 1$, an important gene involved in the dopaminergic system that greatly affects the eating habits of patients with EDBEB, is considered to be very significant for elucidating the molecular disease state of $\mathrm{ED}$ and for clinical perspectives, including diagnosis and treatment.

\section{Conclusion}

In our study, only the Japanese sample sets were used. Furthermore, the sample size was small $(n=204)$. Therefore, the statistical power for detection was low. Moreover, optimum primer sets could not be constructed for analyzing the polymorphisms of exon 15; therefore, the entire exon of the coding region of the $D A T 1$ gene could not be analyzed. Nonetheless, we were able to identify two polymorphisms that are believed to be associated with patients with EDBEB and indicate an association between these mutations and polymorphisms in 3'-UTR VNTR. To identify the $D A T 1$ gene plays a key role in the dopaminergic system of EDBEB, it will be needed to conduct statistical haplotype analysis of rs2270912, rs28363130, and 3'-UTR VNTRs using a larger sample size and functional analysis of rs2270912, rs28363130, and 3'-UTR VNTRs by direct testing in future.

\section{Acknowledgements}

We received detailed guidance from Dr. Kunihiko Shioe and Dr. Nobutaka Motohashi (Department of Neuropsychiatry and Clinical Ethics, Integrated Graduate School of Medicine and Engineering, University of Yamanashi). We received cooperation from Dr. Shigenobu Kanba (Department of Neuropsychiatry, Graduate School of Medicine), Dr. Hiroko Mizuno (Hiroko Mizuno Mental Clinic), and Dr. Yutaka Ono (Center for the Development of Cognitive Behavior Therapy Training) in the collection of samples. We also received advice from Mie Nakazawa, a technician (Department of Neuropsychiatry and Clinical Ethics, Integrated Graduate School of Medicine and engineering, University of Yamanashi), regarding concentration measurement and PCR conditions.

\section{Disclosure Statement}

None of the authors of this paper have any involvement, financial or otherwise, that might bias this work.

\section{References}

[1] Campbell, K. and Peebles, R. (2014) Eating Disorders in Children and Adolescents: State of the Art Review. Pediatrics, 134, 582-592. 
https://doi.org/10.1542/peds.2014-0194

[2] American Psychiatric Association (2013) Diagnostic and Statistical Manual of Mental Disorders, 5th Edition (DSM-5). American Psychiatric Association Publishing, Arlington, VA.

[3] Wiederman, M.W. and Pryor, T. (1996) Substance Use among Women with Eating Disorders. International Journal of Eating Disorders, 20, 163-168. https://doi.org/10.1002/(SICI)1098-108X(199609)20:2<163::AID-EAT6>3.0.CO;2-E

[4] Daniels, E.S., Masheb, R.M., Berman, R.M., Mickley, D. and Grilo, C.M. (1999) Bulimia Nervosa and Alcohol Dependence: A Case Report of a Patient Enrolled in a Randomized Controlled Clinical Trial. Journal of Substance Abuse Treatment, 17, 163-166. https://doi.org/10.1016/S0740-5472(98)00061-0

[5] Matsunaga, H., Kaye, W.H., McConaha, C., Plotnicov, K., Pollice, C., Rao, R. and Stein, D. (1999) Psychopathological Characteristics of Recovered Bulimics who have a History of Physical or Sexual Abuse. The Journal of Nervous and Mental Disease, 187, 472-477. https://doi.org/10.1097/00005053-199908000-00003

[6] Crow, S.J., Peterson, C.B., Swanson, S.A., Raymond, N.C., Specker, S., Eckert, E.D. and Mitchell, J.E. (2009) Increased Mortality in Bulimia Nervosa and Other Eating Disorders. American Journal of Psychiatry, 166, 1342-1346.

https://doi.org/10.1176/appi.ajp.2009.09020247

[7] Berrettini, W. (2004) The Genetics of Eating Disorders. Psychiatry (Edgmont), 1, 18.

[8] Mazzeo, S.E. and Bulik, C.M. (2009) Environmental and Genetic Risk Factors for Eating Disorders: What the Clinician Needs to Know. Child and Adolescent Psychiatric Clinics of North America, 18, 67-82.

https://doi.org/10.1016/j.chc.2008.07.003

[9] Holland, A.J., Sicotte, N. and Treasure, J. (1988) Anorexia Nervosa: Evidence for a Genetic Basis. Journal of Psychosomatic Research, 32, 561-571. https://doi.org/10.1016/0022-3999(88)90004-9

[10] Lilenfeld, L.R., Kaye, W.H., Greeno, C.G., Merikangas, K.R., Plotnicov, K., Pollice, C., Rao, R., Strober, M., Bulic, C.M. and Nagy, L. (1998) A Controlled Family Study of Anorexia Nervosa and Bulimia Nervosa: Psychiatric Disorders in First-Degree Relatives and Effects of Proband Comorbidity. Archives of General Psychiatry, 55, 603-610. https://doi.org/10.1001/archpsyc.55.7.603

[11] Boraska, V., Franklin, C.S., Floyd, J.A., Thornton, L.M., Huckins, L.M., Southam, L., Rayner, N.W., Tachmazidou, I., Klump, K.L., Treasure, J., et al. (2014) A Genome-Wide Association Study of Anorexia Nervosa. Molecular Psychiatry, 19, 1085-1094. https://doi.org/10.1038/mp.2013.187

[12] Yilmaz, Z., Hardaway, J.A. and Bulik, C.M. (2015) Genetics and Epigenetics of Eating Disorders. Advances in Genomics and Genetics, 5, 131-150.

[13] Wise, R.A. (2006) Role of Brain Dopamine in Food Reward and Reinforcement. Philosophical Transactions of the Royal Society of London B: Biological Sciences, 361, 1149-1158. https://doi.org/10.1098/rstb.2006.1854

[14] Avena, N.M. and Bocarsly, M.E. (2012) Dysregulation of Brain Reward Systems in Eating Disorders: Neurochemical Information from Animal Models of Binge Eating, Bulimia Nervosa, and Anorexia Nervosa. Neuropharmacology, 63, 87-96.

[15] Vandenbergh, D.J., Persico, A.M., Hawkins, A.L., Griffin, C.A., Li, X., Jabs, E.W. and Uhl, G.R. (1992) Human Dopamine Transporter Gene (DAT1) Maps to Chromosome 5p15. 3 and Displays a VNTR. Genomics, 14, 1104-1106. 
[16] Fuke, S., Suo, S., Takahashi, N., Koike, H., Sasagawa, N. and Ishiura, S. (2001) The VNTR Polymorphism of the Human Dopamine Transporter (DAT1) Gene Affects GENE Expression. The Pharmacogenomics Journal, 1, 152-156. https://doi.org/10.1038/sj.tpj.6500026

[17] Frieling, H., Römer, K.D., Scholz, S., Mittelbach, F., Wilhelm, J., De Zwaan, M., Jacoby, G.E., Kornhuber, J., Hillemacher, T. and Bleich, S. (2010) Epigenetic Dysregulation of Dopaminergic Genes in Eating Disorders. International Journal of Eating Disorders, 43, 577-583. https://doi.org/10.1002/eat.20745

[18] Spencer, T.J., Biederman, J., Faraone, S.V., Madras, B.K., Bonab, A.A., Dougherty, D. D., Batchelder, H. and Fischman, A.J. (2013) Functional Genomics of Attention-deficit/Hyperactivity Disorder (ADHD) Risk Alleles on Dopamine Transporter Binding in ADHD and Healthy Control Subjects. Biological Psychiatry, 74, 84-89.

[19] Muramatsu, T. and Higuchi, S. (1995) Dopamine Transporter Gene Polymorphism and Alcoholism. Biochemical and Biophysical Research Communications, 211, 28-32. https://doi.org/10.1006/bbrc.1995.1773

[20] Jorm, A.F., Henderson, A.S., Jacomb, P.A., Christensen, H., Korten, A.E., Rodgers, B., Tan, X. and Easteal, S. (2000) Association of Smoking and Personality with a Polymorphism of the Dopamine Transporter Gene: Results from a Community Survey. American Journal of Medical Genetics, 96, 331-334. https://doi.org/10.1002/1096-8628(20000612)96:3<331::AID-AJMG19>3.0.CO;2-0

[21] Gelernter, J., Kranzler, H.R., Satel, S.L. and Rao, P.A. (1994) Genetic Association between Dopamine Transporter Protein Alleles and Cocaine-Induced Paranoia. Neuropsychopharmacology, 11, 195-200. https://doi.org/10.1038/sj.npp.1380106

[22] Prata, D.P., Mechelli, A., Picchioni, M.M., Fu, C.H., Toulopoulou, T., Bramon, E., Walshe, M., Murray, R.M., Collier, D.A. and McGuire, P. (2009) Altered Effect of Dopamine Transporter 3' UTR VNTR Genotype on Prefrontal and Striatal Function in Schizophrenia. Archives of General Psychiatry, 66, 1162-1172.

https://doi.org/10.1001/archgenpsychiatry.2009.147

[23] Shinohara, M., Mizushima, H., Hirano, M., Shioe, K., Nakazawa, M., Hiejima, Y., Ono, Y. and Kanba, S. (2004) Eating Disorders with Binge-Eating Behaviour Are Associated with the s Allele of the 3'-UTR VNTR Polymorphism of the Dopamine Transporter Gene. Journal of Psychiatry and Neuroscience, 29, 134-137.

[24] Mizushima, H., Ono, Y. and Asai, M. (1998) TCI Temperamental Scores in Bulimia Nervosa Patients and Normal Women with and without Diet Experiences. Acta Psychiatrica Scandinavica, 98, 228-230. https://doi.org/10.1111/j.1600-0447.1998.tb10072.x

[25] American Psychiatric Association (1994) Diagnostic and Statistical Manual of Mental Disorders. 4th Edition (DSM-IV), American Psychiatric Association Publishing, Washington DC.

[26] Garner, D.M., Olmsted, M.P., Polivy, J. and Garfinkel, P.E. (1984) The Eating Disorder Inventory Manual. Psychological Assessment Resources.

[27] Chen, B., Stefan, W., Marion, D. and Kari, H. (2009) SNP Tools: A Compact Tool Package for Analysis and Conversion of Genotype Data for MS-Excel. BMC Research Notes, 2, 214. https://doi.org/10.1186/1756-0500-2-214

[28] Sauna, Z.E., Kimchi-Sarfaty, C., Ambudkar, S.V. and Gottesman, M.M. (2007) Silent Polymorphisms Speak: How They Affect Pharmacogenomics and the Treatment of Cancer. Cancer Research, 67, 9609-9612. https://doi.org/10.1158/0008-5472.CAN-07-2377 
[29] Bonfanti, L. (2006) L.PSA-NCAM in Mammalian Structural Plasticity and Neurogenesis. Progress Neurobiology, 80, 129-164.

[30] Sato, C., Hane, M. and Kitajima, K. (2016) Relationship between ST8SIA2, Polysialic Acid and Its Binding Molecules, and Psychiatric Disorders. Biochim Biochimica et Biophysica Acta General Subjects, 1860, 1739-1752.

[31] Isomura, R., Kitajima, K. and Sato, C. (2011) Structural and Functional Impairments of Polysialic Acid by a Mutated Polysialyltransferase Found in Schizophrenia. Journal of Biological Chemistry, 286, 21535-21545. https://doi.org/10.1074/jbc.M111.221143

[32] 1000 Genomes Project Consortium (2010) A Map of Human Genome Variation from Population-Scale Sequencing. Nature, 467, 1061-1073.

https://doi.org/10.1038/nature09534

[33] 1000 Genomes Project Consortium (2012) An Integrated Map of Genetic Variation from 1,092 Human Genomes. Nature, 491, 56-65.

https://doi.org/10.1038/nature11632

[34] Heinz, A., Goldman, D., Jones, D.W., Palmour, R., Hommer, D., Gorey, J.G., Lee, K.S., Linnoila, M. and Weinberger, D.R. (2000) Genotype Influences in Vivo Dopamine Transporter Availability in Human Striatum. Neuropsychopharmacology, 22, 133-139.

[35] Jacobsen, L.K., Staley, J.K., Zoghbi, S.S., Seibyl, J.P., Kosten, T.R., Innis, R.B. and Gelernter, J. (2000) Prediction of Dopamine Transporter Binding Availability by Genotype: A Preliminary Report. American Journal of Psychiatry, 157, 1700-1703. https://doi.org/10.1176/appi.ajp.157.10.1700

[36] Martinez, D., Gelernter, J., Abi-Dargham, A., van Dyck, C.H., Kegeles, L., Innis, R.B. and Laruelle, M. (2001) The Variable Number of Tandem Repeats Polymorphism of the Dopamine Transporter Gene Is Not Associated with Significant Change in Dopamine Transporter Phenotype in Humans. Neuropsychopharmacology, 24, 553-560.

[37] Fung, K.L. and Gottesman, M.M. (2009) A Synonymous Polymorphism in a Common MDR1 (ABCB1) Haplotype Shapes Protein Function. Biochimica et Biophysica Acta (BBA) Proteins and Proteomics, 1794, 860-871.

[38] Reamon-Buettner, S.M., Sattlegger, E., Ciribilli, Y., Inga, A., Wessel, A. and Borlak, J. (2013) Transcriptional Defect of an Inherited NKX2-5 Haplotype Comprising a SNP, a Nonsynonymous and a Synonymous Mutation, Associated with Human Congenital Heart Disease. PLOS ONE, 8, e83295.

https://doi.org/10.1371/journal.pone.0083295 